\title{
A bedtime story about medicine's coming of age
}

\author{
The Making of Modern Medicine: Turning \\ Points in the Treatment of Disease \\ Michael Bliss \\ University of Chicago Press; 2011.
}

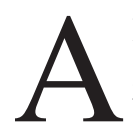

lthough this may seem to be a grandiose title for a 100-page book that can be read in a single sitting, it is if anything an understatement. This slim but elegant work is an expanded version of three presentations the renowned Canadian historian gave as the 2008 Joanne Goodman Lecturer at the University of Western Ontario in London. His three enthralling "case histories," distilled from his definitive books of medical history, are a veritable bedtime story about medicine's coming of age between the late-1880s, with the appointment of Ontario native Dr. William Osler as the inaugural physician-in-chief and professor of medicine at Johns Hopkins Hospital, and the early 1920s, with the discovery and successful use of insulin by four "uneasy collaborators" at the University of Toronto: Drs. J.B. Collip, J.J.R. Macleod, and Fred Banting, assisted by medical student Charley Best.

This was arguably the most innovative and dynamic era in the history of medicine, full of "turning points in humanity's assault on disease," notably advances in anesthesia, surgery, asepsis and sanitation. To Bliss it was also "the time in history when our trust in the capacity of physicians to actually treat disease became established." The common thread among the book's stories, beginning with a consideration of the Montréal smallpox epidemic of 1885 that killed more than 3000 , is the shift of humanity's faith in prayer to a new faith in "secular caregivers to offer salvation from the ravages that disease and time inflict on our bodies."

Bliss' book is not only a medical history primer, it is also a reminder of what

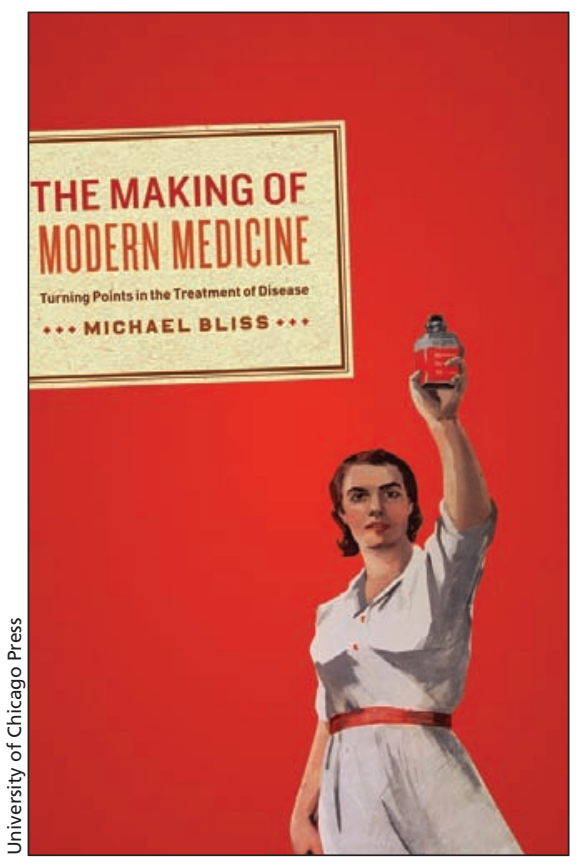

we take for granted. In a brief epilogue, he races through the myriad breakthroughs that flowed throughout the rest of the 20th century, but his heart is clearly with the two visionaries at Hopkins at the outset of the century: Osler and Dr. Harvey Cushing. Encouraged by the open-minded and surgeonfriendly Osler, Cushing was the first to navigate, by his own analogy, "the Northwest passage of surgery": the brain. The father of modern neurosurgery would soon also found the field of endocrinology. And consider this encomium: "William Osler was a oneman hypotenuse of the North Atlantic medical triangle" as a physician "shaped by and shaping British, Canadian, and American cultures."

Perhaps unintentionally, this book also reminds us of lessons that are still unlearned. Even in his bare bones account of the discovery of insulin (drawn from his seminal book on the subject), Bliss highlights the enmity and jealousy between fellow investigators Banting and Macleod, the two recipients of the Nobel Prize in Physiology and Medicine. The overlooking of Callip, who did the actual extraction of insulin from the collected pancreatic substances (and with whom Macleod split his share of the prize money), calls to mind the injustice of the 2003 Nobel Prize in Medicine for applications of Magnetic Resonance Imaging (MRI), when Dr. Raymond Damadian, the MRI's inventor, was not included among the award recipients.

Bliss also soberingly reminds us that Insulin is not a cure for diabetes, but rather an imperfect maintenance therapy. The warm fuzzy glow one feels in reading about a great pioneering experiment is tempered by the global pandemic that type 2 diabetes has become, especially among the young and the reality that an artificial pancreas or other cure remains far off.

Bliss' discussion of the Montréal smallpox outbreak - the worst scourge of this disease in any industrial city during the 19th century — is especially sad and compelling. Between February 1885 and May 1886, there were an average of more than 250 deaths a week - 3164 in all, among 9600 cases in the city - and 2600 more deaths in the surrounding region (among 10300 ). In spite of the fact that vaccination had been used for nearly a century to prevent smallpox and that measures had been developed to contain the spread of the disease, there remained no treatment or cure.

The deaths were predominantly among unvaccinated French-Canadian children. Bliss, echoing Osler's attribution of the death toll to "a negligence absolutely criminal," pins the blame on the fatalism, paranoia, and ignorance of the poor French-Canadian population, who were devoutly religious, distrustful of the maudit anglais, and suspicious of the modern medical concepts of vaccination and quarantine. In these beliefs, 
they were encouraged by antivaccination quacks.

The reader can't help calling to mind not just the many and varied religious sects that refuse vaccinations to this day, but also the many thousands of New Age parents, most famously in Southern California, who, preventing their children from being immunized in the misguided belief that vaccines cause autism, have helped fan a resurgence of pertussis and outbreaks of measles. ${ }^{1}$ Even more disturbing is the false belief that we have conquered AIDS. In spite of pharmaceutical advances, AIDS remains a global plague without a cure.

As engaging as the book is, it still reads a bit too much like an oral presentation. Ideally, it should have included an audio $\mathrm{CD}$ of the original lectures (or at least a link to them online), and hopefully will be published in French.
With the decline in courses in the history of medicine at medical schools, The Making of Modern Medicine should be required reading for every entering medical student, and then revisited and discussed after the student has had some experience interacting with patients.

We urgently need to get Osler's message, channeled by Bliss, to the next generation of physicians about the eternal importance of spirituality in medicine. One of the most touching and almost too-good-to-be-true moments described in The Making of Modern Medicine is of Osler's exemplification of the art of healing by his feeding of a sliced peach every day at bedside to a little boy with whooping cough.

And in a heart-warming historical twist at the close of the book, Bliss connects Osler, Osler's father, and Banting in a deeply personal way. Osler was the devoted son of an Anglican priest - a "backwoods clergyman cum physician" in rural Ontario — who himself "ministered to the sick with priestly caring." One-hundred-and-fifty years later, through the multifarious strides in the diagnosis and treatment of disease, all physicians should continue to aspire to this same ideal.

\section{Alan Blum MD}

Professor and Gerald Leon Wallace MD Endowed Chair in Family Medicine

University of Alabama School of Medicine Tuscaloosa, Ala.

\section{Reference}

1. Retraction - ileal-lymphoid-nodular hyperplasia, non-specific colitis and pervasive development disorder in children. The Lancet 2010;375:445.

CMAJ 2012. DOI:10.1503/cmaj.111023

\section{ENCOUNTERS}

\section{Thrown into the rose}

$\mathrm{T}$ he physician is having a hard time getting the tube into the 600-gram infant's tiny orifices: mini nostrils and a mouth into which I could barely fit my pinky. The goal is to allow for proper and easier ventilation after many an oxygen desaturation, bagging and suctioning episode.

And what is my job? To hold baby down. This tiny little thing squirming and crying with its teeny-tiny limbs and tiny little rib cage moving up and down and baby abdomen twisting from side to side, writhing in distress. So I gently hold her limbs down and out of the way of the people who are trying to save her life, really. But I also proffer my finger for her to hold onto in her delicate, minuscule hand. And she squeezes hard, with all her might, through the whole ordeal. I am there to hold her hand. That is all I can do for her right now.

She is so small, but in all her anguish there is surprising strength in that grasp. She squeezes till her fingers and toes are ghostly pale. Her oxygen saturation plummets and then comes back up with every attempt to intubate, and she cries and writhes and squeezes my finger. I

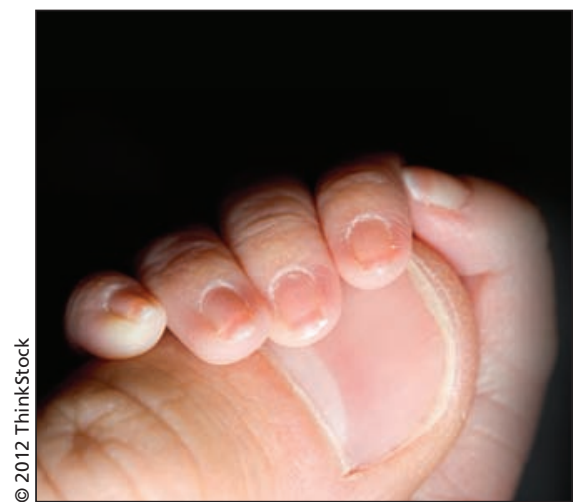

tap her feet to help stimulate her and also to reassure her that here I am, baby, I am still here, I am right here, here. It is torture to watch this little thing fight for her life, struggling relentlessly with every effort. And the tears well up, threatening to spring from my eyes. I hold it together - of course I do, that's my job and my function here. I pray and I pray and I do what I'm told, and I help suction and I hold baby's hand. And also I love her because everything we do in medicine is so vitally important, but love heals too and she needs my love in all that frenzy. So I just stand there and hold her hand and love her like she was a part of my soul. And then she is stable. She does not die in my arms as she had in the morbid image that flashed in my mind earlier that morning on the metro. She is alive and more stable than she was before the intubation.

That's the rose: the spiral of fragrant petals, blood red, silky soft in its heart, and perilous anywhere else around it. It is beautiful, delicate and ethereal, blossoming, drooping, then perking up again. That's where I flew for a few eternal moments in a long and difficult day for many a baby in the neonatal intensive care unit. In some ways, it's true that you should not get too emotionally attached, but there is so much more to learn, to gain and to give if you do allow your heart to be opened. If you choose to go there, it is worth all the pieces of your soul and every breath of your life.

\section{Naila Ramji BA}

MD candidate, Class of 2012

McGill University

Montréal, Que.

CMAJ 2012. DOI:10.1503/cmaj.101609 